\title{
Two concurrent outbreaks of hepatitis A highlight the risk of infection for non-immune travellers to Morocco, January to June 2018
}

Martyna Gassowski ${ }^{1,2,3,4}$, Kai Michaelis ${ }^{1,5}$, Jürgen J. Wenzel ${ }^{1,6}$, Mirko Faber $^{5}$, Julie Figoni' ${ }^{7}$, Lina Mouna ${ }^{8}$, Ingrid HM Friesema9, Harry Vennema ${ }^{10}$, Ana Avellon ${ }^{11}$, Carmen Varela ${ }^{12}$, Lena Sundqvist ${ }^{13}$, Josefine Lundberg Ederth ${ }^{14}$, James Plunkett ${ }^{15}$, Koye Balogun ${ }^{15}$, Siew Lin Ngui ${ }^{15}$, Sofie Elisabeth Midgley ${ }^{16}$, Sofie Gillesberg Lassen ${ }^{17}$, Luise Müller ${ }^{17}$

1. These authors contributed equally to this work

2. Department for Infectious Disease Epidemiology, Robert Koch Institute (RKI), Berlin, Germany

3. Postgraduate Training for Applied Epidemiology (PAE, German Field Epidemiology Training Programme), Robert Koch Institute, Berlin, Germany

4. European Programme for Intervention Epidemiology Training (EPIET), European Centre for Disease Prevention and Control (ECDC), Stockholm, Sweden

5. Department for Infectious Disease Epidemiology, Unit of Gastrointestinal Infections, Zoonoses, and Tropical Infections, Robert Koch Institute (RKI), Berlin, Germany

6. National Consultant Laboratory for HAV and HEV, Institute of Clinical Microbiology and Hygiene, University Medical Centre Regensburg, Regensburg, Germany

7. Santé Publique France, French National Public Health Agency, Saint-Maurice, France

8. AP-HP, National Reference Centre for Enterically Transmitted Hepatitis Viruses, Paul Brousse hospital, Villejuif, France.

9. Centre for Infectious Diseases, Epidemiology and Surveillance, Centre for Infectious Disease Control, National Institute for Public Health and the Environment (RIVM), Bilthoven, the Netherlands

10. Centre for Infectious Diseases Research, Diagnostics and Screening, Centre for Infectious Disease Control, National Institute for Public Health and the Environment (RIVM), Bilthoven, the Netherlands

11.11 Hepatitis Unit, National Center of Microbiology, Instituto de Salud Carlos III, Madrid, Spain

12. National Centre of Epidemiology, Instituto de Salud Carlos III, CIBER Epidemiología y Salud Pública, Madrid, Spain

13. Department of Communicable Disease Control and Health Protection, the Public Health Agency of Sweden, Stockholm, Sweden

14. Department of Microbiology, the Public Health Agency of Sweden, Stockholm, Sweden

15. National Infection Service, Public Health England, London, United Kingdom

16. Department of Virus \& Microbiological Special Diagnostics, Statens Serum Institut, Copenhagen, Denmark

17. Department of Infectious Disease Epidemiology and Prevention, Statens Serum Institut, Copenhagen, Denmark

Correspondence: Kai Michaelis (MichaelisK@rki.de)

Citation style for this article:

Gassowski Martyna, Michaelis Kai, Wenzel Jürgen J., Faber Mirko, Figoni Julie, Mouna Lina, Friesema Ingrid HM, Vennema Harry, Avellon Ana, Varela Carmen, Sundqvist Lena, Lundberg Ederth Josefine, Plunkett James, Balogun Koye, Ngui Siew Lin, Midgley Sofie Elisabeth, Gillesberg Lassen Sofie , Müller Luise. Two concurrent outbreaks of hepatitis A highlight the risk of infection for non-immune travellers to Morocco, January to June 2018. Euro Surveill. 2018;23(27):pii=1800329. https://doi.org/10.2807/1560-7917.ES.2018.23.27.1800329

From January to June 2018, two ongoing hepatitis A outbreaks affected travellers returning from Morocco and cases in Europe without travel history, resulting in 163 patients in eight European countries. Most interviewed travel-related cases were unaware of the hepatitis A risk in Morocco. Molecular analysis revealed two distinct hepatitis A virus (HAV) strains (subgenotype IA DK2018_231; subgenotype IB V18-16428). Vaccination recommendations should be emphasised to increase awareness among non-immune travellers to Morocco and HAV-endemic countries.

We report on two distinct hepatitis A virus strains that are causing cases in travellers returning from Morocco and autochthonous cases in several European countries between 1 January and 18 June 2018 .

The alert

On 2 May 2018, Denmark reported a cluster of hepatitis $A$ virus (HAV) infections with the subgenotype IA strain DK2018_231, through the European Centre for Disease Prevention and Control (ECDC)'s Epidemic Intelligence Information System (EPIS) for food- and waterborne diseases and zoonoses (FWD). One of the three confirmed cases had travelled to Morocco. In response, five additional European Union (EU) countries (France, Germany, the Netherlands, Spain and the United Kingdom (UK)) reported cases $(n=20)$ infected with the same strain between 21 January and 10 April 2018. Concurrently, Germany reported to EPIS that it observed more cases of hepatitis A with travel history to Morocco than expected, compared with the same period in the previous 5 years. Molecular analysis of the HAV VP1/P2A region revealed an unrelated cluster of the HAV subgenotype IB strain $V_{18}-16428$. Cases infected with this unrelated strain were also reported from France, the Netherlands, Sweden and UK.

The appearance of clusters with a link to Morocco triggered further epidemiological investigations. 
Case definitions for confirmed travel-related or autochthonous hepatitis A cases infected with the subgenotype IA virus strain DK2018_231 or the subgenotype IB virus strain V18-16428

\begin{tabular}{|c|c|}
\hline \multicolumn{2}{|l|}{ Travel-related confirmed cases } \\
\hline \multicolumn{2}{|c|}{$\begin{array}{l}- \text { An EU/EEA resident with laboratory-confirmed hepatitis } A \text { and date of sympt } \\
\text { available or if the case is asymptomatic) on or after } 1 \text { January } 2018 \\
\text { and } \\
\text { - with a travel history to Morocco in the } 50 \text { days before symptoms onset } \\
\text { And }\end{array}$} \\
\hline Cluster with subgenotype IA & Cluster with subgenotype IB \\
\hline $\begin{array}{l}\text { - a sequence with } \geq 99.4 \% \text { identity to the HAV subgenotype } \\
\text { IA outbreak strain } \mathrm{DK}_{2018} 231 \text {, based on an overlapping } \\
\text { fragment at the } \mathrm{P}_{1} / \mathrm{P}_{2} \mathrm{~A} \text { region. }\end{array}$ & $\begin{array}{l}\text { - a sequence with } \geq 99.4 \% \text { identity to the HAV subgenotype IB } \\
\text { outbreak strain } V_{1} 8-16428 \text {, based on an overlapping fragment at the } \\
\text { VP1/P2A region. }\end{array}$ \\
\hline \multicolumn{2}{|l|}{ Autochthonous confirmed cases } \\
\hline \multicolumn{2}{|c|}{$\begin{array}{l}\text { - An EU/EEA resident with laboratory-confirmed hepatitis A and date of symptoms } 0 \\
\text { available or if the case is asymptomatic) on or after } 1 \text { January } 2018 \\
\text { and } \\
\text { - without a travel history out of the EU/EEA in the } 50 \text { days before symptoms onset } \\
\text { And }\end{array}$} \\
\hline Cluster with subgenotype IA & Cluster with subgenotype IB \\
\hline $\begin{array}{l}\text { - a sequence with } \geq 99.4 \% \text { identity to the HAV subgenotype } \\
\text { IA outbreak strain } D K 2018 \text { 231, based on an overlapping } \\
\text { fragment at the } V P_{1} / P_{2} A \text { region }\end{array}$ & $\begin{array}{l}\text { - a sequence with } \geq 99.4 \% \text { identity to the HAV subgenotype IB } \\
\text { outbreak strain } V_{1} 8-16428 \text {, based on an overlapping fragment at the } \\
V_{1} / P_{2} A \text { region }\end{array}$ \\
\hline \multicolumn{2}{|l|}{ Travel-related possible cases } \\
\hline \multicolumn{2}{|c|}{$\begin{array}{l}- \text { An EU/EEA resident with laboratory-confirmed hepatitis A and date of sy } \\
\text { available or if the case is asymptomatic) on or after } 1 \text { January } 2018 \\
\text { and }\end{array}$} \\
\hline
\end{tabular}

EU/EEA: European Union/European Economic Area; HAV: hepatitis A virus.

In order to consider possible mutations, we included closely related strains with a cut-off of 2 nucleotides ( $99.4 \%$ identity) in the case definition.

\section{Case definitions and outbreak curve}

For the investigation of the two clusters, the case definitions in the Box were used. The Figure shows the epidemiological curve depicting both clusters.

\section{Subgenotype IA cluster (DK2018_231)}

As at 18 June 2018, 55 cases belonging to the subgenotype IA-cluster were reported from eight European countries. The UK reported the highest number of cases $(n=36)$. Denmark, France, Germany, Ireland, the Netherlands, Spain and Sweden each reported between one and six cases. Some few cases $(n=22 / 55)$ identified in Ireland, Spain and the UK differ from strain DK2018_231 by one or two nucleotides in the VP1/P2A junction.
Onset of symptoms among the cases ranged between mid-January and mid-June 2018. Cases were between 3 and 81 years old with a median of 31 years (interquartile range (IQR): $12.5-52$ years); $47 \%(n=26 / 55)$ were female. Three cases reported travel to Morocco within 50 days before disease onset; one case in their early $50 s$ who had no known pre-existing conditions, died as a result of $\mathrm{HAV}$ infection.

Variants of strain DK2018_231 differing by only one or two nucleotides are considered as part of this cluster. The occurrence of closely related strains of HAV have been observed in other major food-borne outbreaks [1-3]. It is, however, still possible that cases actually belong to separate transmission chains. 


\section{FIGURE}

Number of hepatitis A virus cases by case definition, hepatitis A virus subgenotype cluster and week of disease onset, 1 January-18 June $2018(\mathrm{n}=163)$

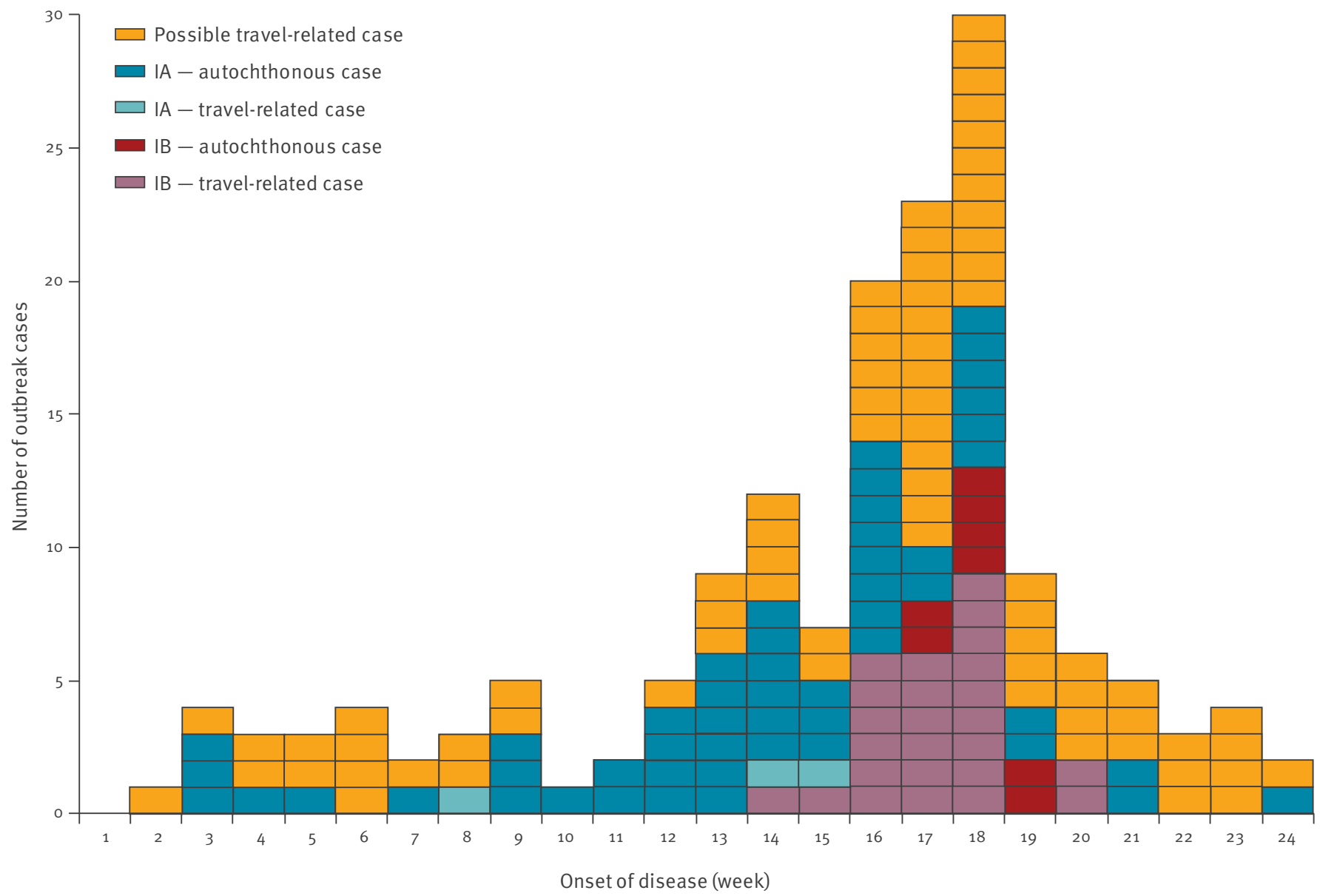

2018

IA: subgenotype IA, strain DK2018_231; IB: subgenotype IB strain V18-16428.

\section{Subgenotype IB cluster (V18-16428)}

As at 18 June 2018, the subgenotype IB-cluster consisted of 33 confirmed cases; 25 travel-related and eight autochthonous (Table). Most cases were reported by Germany $(n=15)$, France $(n=8)$ and the UK $(n=6)$, with Sweden and the Netherlands only reporting one and three cases, respectively. Sequencing results of the $\mathrm{VP}_{1} / \mathrm{P}_{2} \mathrm{~A}$ junctions revealed a $100 \%$ identity. Onset of symptoms ranged from the beginning of April to midMay. All travel-related cases reported travel to Morocco in March. The overall age range of cases were between 8 and 76 years, with a median of 51 years (IQR: $26-61$ years); $55 \%(n=18 / 33)$ were female

\section{Early results from case interviews in Germany and France}

The travel-related cases in Germany were initially suspected to belong to the IA cluster, but the sequencing results revealed a different subgenotype. A case-control study of the German cases is underway, and 16 travel-related cases (8 confirmed, 8 possible) and four autochthonous cases have been interviewed so far for potential exposures. All autochthonous cases have reported consumption of food items brought home by travellers returning from Morocco, with dates being the only food item reported by all four cases. Among the 16 travel-associated cases, 14 reported date consumption during their stay in Morocco. In France, one patient reported bringing dates back from Morocco and eating these together with two other persons, all three of whom developed symptoms after the same incubation time.

Based on these preliminary results, dates are currently the suspected vehicle in this cluster, though investigation is ongoing.

\section{Vaccination status}

Information regarding hepatitis A vaccination status was collected from the German travel-related cases via interview, including reasons for non-vaccination. Preliminary results show that of the 15 travel-related 
Number of travel-related and autochthonous cases of hepatitis A, by country of origin and hepatitis A virus subgenotype, 1 January-18 June $2018(\mathrm{n}=163)$

\begin{tabular}{|c|c|c|c|c|c|}
\hline \multirow[b]{2}{*}{ Country of origin } & \multicolumn{2}{|c|}{$\begin{array}{c}\text { Number of confirmed cases, subgenotype IA, } \\
\text { DK2018_231 }\end{array}$} & \multicolumn{2}{|c|}{$\begin{array}{l}\text { Number of confirmed cases, subgenotype IB, } \\
\qquad V_{18}-16428\end{array}$} & \multirow{2}{*}{$\begin{array}{c}\text { Number of possible } \\
\text { cases } \\
\text { Travel-related }\end{array}$} \\
\hline & Travel-related & Autochthonous & Travel-related & Autochthonous & \\
\hline Denmark & 1 & 5 & 0 & 0 & 2 \\
\hline France & 1 & 0 & 6 & 2 & 43 \\
\hline Germany & 1 & 0 & 9 & 6 & 15 \\
\hline Ireland & 0 & 1 & 0 & 0 & 0 \\
\hline The Netherlands & 0 & 4 & 3 & 0 & 1 \\
\hline Spain & 0 & 5 & 0 & 0 & 14 \\
\hline Sweden & 0 & 1 & 1 & 0 & 0 \\
\hline UK & 0 & 36 & 6 & 0 & 0 \\
\hline Total & 3 & 52 & 25 & 8 & 75 \\
\hline
\end{tabular}

UK: United Kingdom.

cases (one case refused to be re-interviewed), 13 were either not vaccinated or unsure of their vaccination status. Eleven cases stated that they had been unaware of the risk of HAV in Morocco, while six reported that they did not know there was a vaccination against hepatitis A. During the interviews, several cases stated that there was a lack of information regarding vaccination recommendations for Morocco in the travel guides and tour operator documents they had used when preparing for their trip.

Unvaccinated travel-related cases were also reported from Denmark $(n=3)$, France $(n=41)$, the Netherlands $(n=3)$ and Spain $(n=5)$; reasons for non-vaccination were not collected. Vaccination status was not available for all other travel-related cases from these countries or from Ireland, Sweden and the UK.

\section{Discussion and conclusion}

The occurrence of the two concurrent HAV clusters in the first 6 months of 2018 serve as a reminder of the risk of contracting hepatitis A in Morocco, a country with intermediate endemicity $[4,5]$. HAV subgenotypes IA and IB are known to circulate in Morocco and strain DK2018_231 has been observed in sporadic cases with travel history to Morocco in previous years [6-8]. Despite the different characteristics of the two reported clusters, cases with a travel history to Morocco feature in both. In a recent study of European travellers, Turkey, Egypt and Morocco were listed as the top three destinations for acquiring travel-associated hepatitis $A$ and accounted for one third of cases in the period 2009-15 [9]. The epidemiological link to Morocco is more apparent in cluster IB, where the majority of cases had confirmed travelling to Morocco and all interviewed autochthonous cases had reported consuming food items brought home from there.

In the IA cluster, only three cases had travelled to Morocco. However, the large proportion of autochthonous cases and their spatial distribution in this cluster suggest that an imported food item may have served as the vehicle in this outbreak. Large food-borne hepatitis A outbreaks from frozen berries and semi-dried tomatoes have previously affected European countries, further indicating that imported contaminated food products pose a risk to the increasingly susceptible general population in Europe [10-13].

The outbreaks described here illustrate the increased risk that non-immune travellers face when visiting HAVendemic areas like Morocco. All of the eight countries where cases occurred have explicit recommendations of hepatitis A vaccination for travel to endemic countries, in accordance with World Health Organization (WHO) recommendations $[14,15]$. Yet it appears that it is not uncommon for people to travel unvaccinated to HAV-endemic countries. An outbreak investigation of hepatitis $A$ in travellers to Egypt between 2012 and 2013 found a high proportion of travellers who were not immunised before travelling $[16,17]$. Interviews with the German cases have rendered similar results, suggesting that there may be an information gap regarding both the risk of hepatitis $A$ and the availability of a safe and effective vaccine.

\section{Conclusions}

Thus, vaccination recommendations for hepatitis $A$ need to be repeatedly emphasised, particularly before and during peak travel seasons. In order to better reach individuals travelling to endemic countries, we propose engaging travel companies and airlines to inform and remind travellers about vaccination recommendations, as has been suggested by others $[16,18]$. Special attention should also be given to populations with a Moroccan origin living in the EU/EEA, who may regularly be travelling to Morocco. These populations need to be alerted that particularly their children are most likely susceptible to HAV infection and should be vaccinated [19]. Finally, as hepatitis $A$ vaccination does 
not protect from many other food-borne infections additional recommendations to follow sound hygiene including hand hygiene should be given to the public.

\section{Acknowledgements}

First, we thank the European Centre for Disease Prevention and Control (ECDC)'s Food- and Waterborne Diseases and Zoonoses team, particularly Ettore Severi and Johanna Takkinen for their support of this joint investigation. We also thank Lelia Thornton, HSE - Health Protection Surveillance Centre, Dublin, Ireland for sharing information on the Irish hepatitis A patient. Moreover, we greatly acknowledge the work of local and state health departments for their support of epidemiological investigations and molecular surveillance.

\section{Conflict of interest}

None declared.

\section{Authors' contributions}

All authors contributed to data collection, analysis and interpretation from respective countries (Germany: MG, KM, JJW, MF; France: JF, LMo; the Netherlands: IHMF, HV; Spain: AA, CV; Sweden: LS, JLE; the United Kingdom: JP, KB, SLN; Denmark: SEM, SGL, LMü). LMü and KM posted initial messages in EPIS. JJW identified the outbreak strain V18-16428. KM coordinated this joint outbreak report. MG and KM have jointly drafted and written the manuscript. All authors critically revised the work and approved the final version.

\section{References}

1. Frank C, Walter J, Muehlen M, Jansen A, van Treeck U, Hauri $A M$, et al. Major outbreak of hepatitis A associated with orange juice among tourists, Egypt, 2004. Emerg Infect Dis. 2007;13(1):156-8. https://doi.org/10.3201/eid1301.060487 PMID: 17370535

2. Amon JJ, Devasia R, Xia G, Nainan OV, Hall S, Lawson B, et al. Molecular epidemiology of foodborne hepatitis a outbreaks in the United States, 2003. J Infect Dis, 2005;192(8):1323-30. https://doi.org/10.1086/462425 PMID: 16170748

3. Wheeler C, Vogt TM, Armstrong GL, Vaughan G, Weltman A, Nainan OV, et al. An outbreak of hepatitis A associated with green onions. N Engl J Med. 2005;353(9):890-7. https://doi. org/10.1056/NEJMoa050855 PMID: 16135833

4. Koroglu M, Jacobsen KH, Demiray T, Ozbek A, Erkorkmaz U, Altindis M. Socioeconomic indicators are strong predictors of hepatitis A seroprevalence rates in the Middle East and North Africa. J Infect Public Health. 2017;10(5):513-7. https://doi. org/10.1016/j.jiph.2016.09.020 PMID: 28162965

5. Jacobsen KH, Wiersma ST. Hepatitis A virus seroprevalence by age and world region, 1990 and 2005 . Vaccine. 2010;28(41):6653-7. https://doi.org/10.1016/j. vaccine.2010.08.037 PMID: 20723630

6. D’Andrea L, Pérez-Rodríguez Fl, de Castellarnau M, Manzanares S, Lite J, Guix S, et al. Hepatitis A virus genotype distribution during a decade of universal vaccination of preadolescents. Int J Mol Sci. 2015;16(4):6842-54. https://doi. org/10.3390/ijms16046842 PMID: 25815599

7. Faber MS, Stark K, Behnke SC, Schreier E, Frank C. Epidemiology of hepatitis A virus infections, Germany, 20072008. Emerg Infect Dis. 2009;15(11):1760-8. https://doi. org/10.3201/eid1511.090214 PMID: 19891863

8. European Centre for Disease Prevention and Control (ECDC). Multi-country outbreak of hepatitis A virus genotype IA infections affecting EU countries in 2018 - 21 May 2018 Stockholm: ECDC; 2018. Available from: https://ecdc.europa. eu/sites/portal/files/documents/21-05-2018-RRA-Hepatitis-Amulticountry-outbreak-EU.pdf.

9. Beauté J, Westrell T, Schmid D, Müller L, Epstein J, Kontio M, et al. Travel-associated hepatitis A in Europe, 2009 to 2015. Euro
Surveill. 2018;23(22):1700583. https://doi.org/10.2807/15607917.ES.2018.23.22.1700583 PMID: 29871720

10. Severi E, Verhoef L, Thornton L, Guzman-Herrador BR, Faber M, Sundqvist $L$, et al. Large and prolonged food-borne multistate hepatitis A outbreak in Europe associated with consumption of frozen berries, 2013 to 2014. Euro Surveill. 2015;20(29):21192. https://doi.org/10.2807/1560-7917.ES2015.20.29.21192 PMID: 26227370

11. Gillesberg Lassen S, Soborg B, Midgley SE, Steens A, Vold $L$, Stene-Johansen K, et al. Ongoing multi-strain food-borne hepatitis A outbreak with frozen berries as suspected vehicle: four Nordic countries affected, October 2012 to April 2013. Euro Surveill. 2013;18(17):20467. https://doi.org/https://10.2807/ ese.18.17.20467 PMID: 23647625

12. Fournet $N$, Baas D, van Pelt W, Swaan C, Ober H, Isken L, et al. Another possible food-borne outbreak of hepatitis $A$ in the Netherlands indicated by two closely related molecular sequences, July to October 2011. Euro Surveill. 2012;17(6):20079. https://doi.org/https://10.2807/ ese.17.06.20079 PMID: 22340976

13. Carvalho C, Thomas H, Balogun K, Tedder R, Pebody R, Ramsay $M$, et al. A possible outbreak of hepatitis $A$ associated with semi-dried tomatoes, England, July-November 2011. Euro Surveill. 2012;17(6):20083. https://doi.org/https://10.2807/ ese.17.06.20083 PMID: 22340975

14. European Centre for Disease Prevention and Control (ECDC). Hepatitis A virus in the EU/EEA, 1975-2014. Stockholm: ECDC; 2016. Available from: https://ecdc.europa.eu/sites/portal/ files/media/en/publications/Publications/hepatitis-a-virus-EUEEA-1975-2014.pdf

15. World Health Organization (WHO). WHO position paper on hepatitis A vaccines - June 2012. Wkly Epidemiol Rec. 2012;87(28/29):261-76. PMID: 22905367

16. MacDonald E, Steens A, Stene-Johansen K, Gillesberg Lassen S, Midgley S, Lawrence J, et al. Increase in hepatitis A in tourists from Denmark, England, Germany, the Netherlands, Norway and Sweden returning from Egypt, November 2012 to March 2013. Euro Surveill. 2013;18(17):20468. https://doi.org/ https://10.2807/ese.18.17.20468 PMID: 23647624

17. Sane J, MacDonald E, Vold L, Gossner C, Severi E, on behalf of the International OutbOutbreak Investigation Team. Multistate foodborne hepatitis A outbreak among European tourists returning from Egypt--need for reinforced vaccination recommendations, November 2012 to April 2013. Euro Surveill. 2015;20(4):21018. https://doi.org/10.2807/1560-7917. ES2015.20.4.21018 PMID: 25655054

18. Ward M, Borgen K, Mazick A, Muehlen M. Hepatitis A vaccination policy for travellers to Egypt in eight European countries, 2004. Euro Surveill. 2006;11(1):592. https://doi. org/10.2807/esm.11.01.00592-en

19. Whelan J, Sonder G, van den Hoek A. Declining incidence of hepatitis A in Amsterdam (The Netherlands), 1996-2011: second generation migrants still an important risk group for virus importation. Vaccine. 2013;31(14):1806-11. https://doi. org/10.1016/j.vaccine.2013.01.053 PMID: 23395735

\section{License and copyright}

This is an open-access article distributed under the terms of the Creative Commons Attribution (CC BY 4.0) Licence. You may share and adapt the material, but must give appropriate credit to the source, provide a link to the licence, and indicate if changes were made.

This article is copyright of the authors or their affiliated institutions, 2018. 